US Army Corps

of Engineers ${ }_{\circledast}$

Engineer Research and

Development Center

NASA Research Opportunities in Space and Earth Science (ROSES)

Improving Snow Estimates over the Red River

Basin during the Spring Using Empirical

Relationships Between Satellite Snow Water

Equivalent and Snow-Covered Area

Theodore W. Letcher, Carrie Vuyovich, and Jennifer Jacobs

December 2019
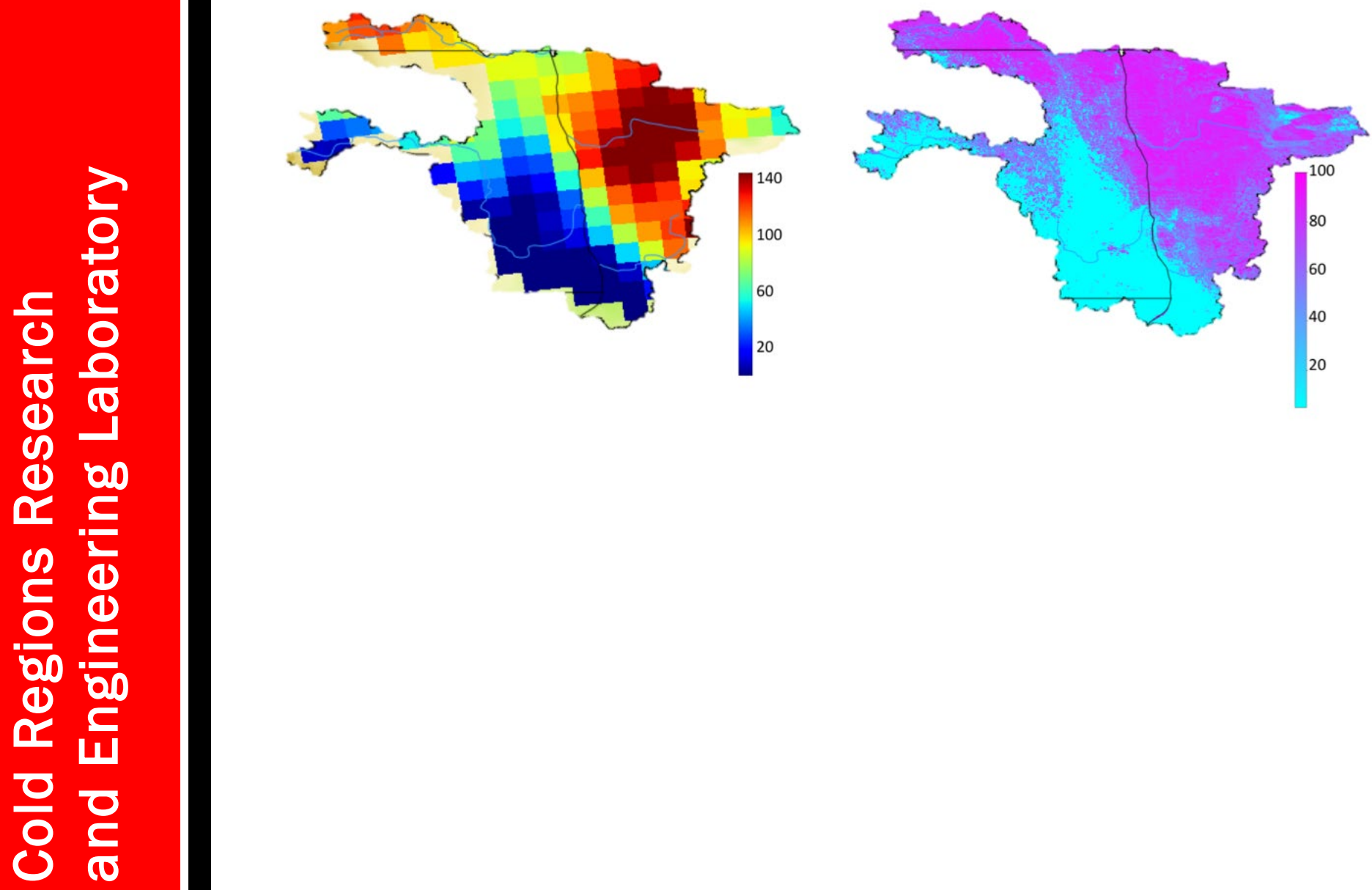
The U.S. Army Engineer Research and Development Center (ERDC) solves the nation's toughest engineering and environmental challenges. ERDC develops innovative solutions in civil and military engineering, geospatial sciences, water resources, and environmental sciences for the Army, the Department of Defense, civilian agencies, and our nation's public good. Find out more at www.erdc.usace.army.mil.

To search for other technical reports published by ERDC, visit the ERDC online library at http://acwc.sdp.sirsi.net/client/default. 


\section{Improving Snow Estimates over the Red River Basin during the Spring Using Empirical Relationships Between Satellite Snow Water Equivalent and Snow-Covered Area}

Theodore W. Letcher

U.S. Army Engineer Research and Development Center (ERDC)

Cold Regions Research and Engineering Laboratory (CRREL)

72 Lyme Road

Hanover, NH 03755-1290

Carrie Vuyovich

National Aeronautics and Space Administration (NASA)

Goddard Space Flight Center

8800 Greenbelt Rd

Greenbelt, MD 20771

Jennifer Jacobs

Civil and Environmental Engineering at the University of New Hampshire

Gregg Hall, Rm 240

Durham, NH 03824

Final Report

Approved for public release; distribution is unlimited.

Prepared for National Aeronautics and Space Administration (NASA)

NASA Headquarters

300 E. Street SW, Suite 5R30

Washington, DC 20546

Under "Research Opportunities in Space and Earth Science (ROSES)," MIPR 80HQTR18T0049 


\section{Abstract}

Assessing rapid changes in snow storage during spring is critical for predicting river flooding along the Red River in the north-central United States. While passive microwave retrievals of snow water equivalent (SWE) over the Red River water basin are generally accurate, they are less certain during the spring due to snowmelt events. These degrade the SWE retrieval algorithms by introducing liquid water into the snowpack. To increase confidence in daily SWE estimates over the Red River basin, we use the concept of a SWE depletion curve to relate basin mean SWE to snowcovered area (SCA) as determined by the MODIS cloud-gap-filled daily SCA product. We use this concept to derive an empirical relationship between SWE and SCA over the Red River basin from 11 years of satellite observations (2007-2018). This relationship relies on the climatologically accurate passive microwave SWE product to mitigate acute inaccuracies in daily SWE retrievals caused by data gaps and complicated snowpack properties. In a comparison of SWE derived from the empirical SCA relationship to SWE estimated from the Snow Data Assimilation product, we find substantial quantitative improvement over the passive microwave SWE product during the spring melt season.

DISCLAIMER: The contents of this report are not to be used for advertising, publication, or promotional purposes. Citation of trade names does not constitute an official endorsement or approval of the use of such commercial products. All product names and trademarks cited are the property of their respective owners. The findings of this report are not to be construed as an official Department of the Army position unless so designated by other authorized documents. 


\section{Contents}
Abstract
ii

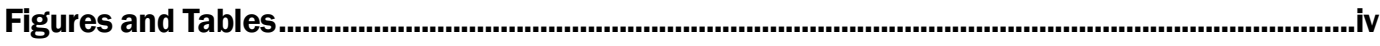

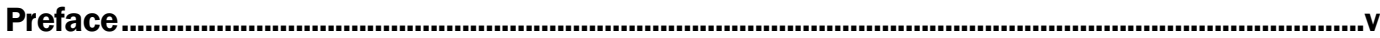

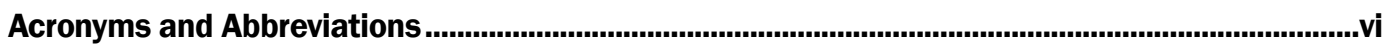

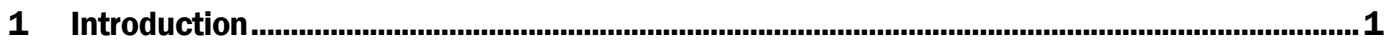

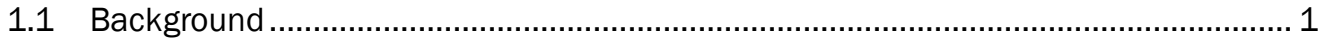

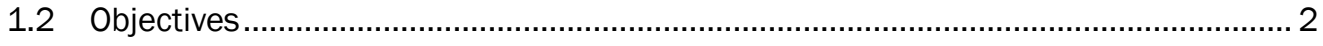

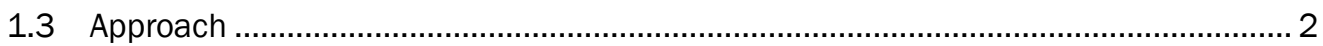

2 Data and Methods ........................................................................................................................... 4

2.1 MODIS cloud-gap-filled snow-covered area............................................................. 4

2.2 NSIDC snow water equivalent ......................................................................... 4

2.3 Snow-depletion-curve derivation .................................................................... 5

2.4 Snow Data Assimilation System evaluation data set................................................ 7

2.5 Red River Basin data masking........................................................................... 8

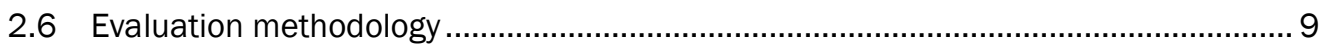

2.7 SDC climatological size requirements .............................................................. 10

2.8 SDC spatial patterns ...................................................................................... 10

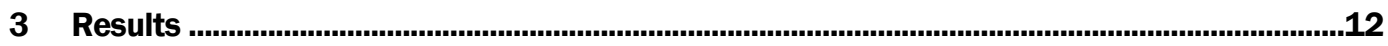

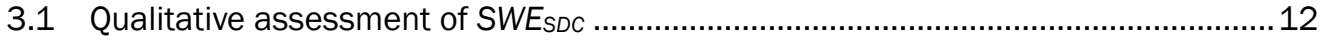

3.2 Bulk quantitative analysis ........................................................................ 14

3.3 SDC climatological size requirements analysis.................................................... 15

3.4 Subbasin statistical analysis........................................................................... 17

4 Conclusions.................................................................................................................................19

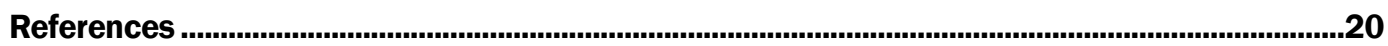

\section{Report Documentation Page}




\section{Figures and Tables}

\section{Figures}

1 Map of the continental United States with the inset showing the region

surrounding the Red River Basin. Shading shows terrain elevation.

2 SDC illustration. SCA scattered against $W^{*}$. Colors indicate date. The polynomial-fitted SDC is shown as a dashed line.

3 Mean SDC (thick black line). Each dashed line corresponds to the SDC for an individual year. Point colors indicate the day of the melt season with cool colors indicating the beginning of snowmelt. SCA percent is the average over the RRB, and $S W E^{*}$ is the normalized SWE (SWE/SWE $E_{\max }$ )

4 Comparison of NSIDC SWE (left), SNODAS SWE (center), and MODIS cloud-gap-filled SCA (right) from 10 March 2014

5 Time series showing SWESDC, SWENSIDC, and SWESNODAS from the date of max SWE to 31 May for each of the 11 water years in the data set.

6 Scatter-plot comparison of SWENSIDC Vs. SWESNODAS (bottom) and SWESDC vs. SWESNODAS (top). The black dashed lines show the one-to-one relationship in each figure

7 RMSE (top), percent bias (middle), and $r^{2}$ (bottom) as a function of years in the SDC data set.

$8 S W E_{N S I D C}$ vs. SWESNODAS (left) and SWESDC vs. SWESNODAS (right). In all figures, warm colors indicate more accurate results than cool colors 17

\section{Tables}

1 Coefficients for $f^{*} S D C(S C A)$, representing an average of coefficients from 2007 to 2018 


\section{Preface}

This study was conducted for the National Aeronautics and Space Administration (NASA) under "Research Opportunities in Space and Earth Science (ROSES),” MIPR 80HQTR18To049.

The work was performed by the Terrestrial and Cryospheric Sciences Branch of the Research and Engineering Division, U.S. Army Engineer Research and Development Center, Cold Regions Research and Engineering Laboratory (ERDC-CRREL). At the time of publication, Dr. John Weatherly was Branch Chief; and Mr. J. D. Horne was Division Chief. The Deputy Director of ERDC-CRREL was Mr. David P. Ringelberg, and the Director was Dr. Joseph L. Corriveau.

COL Teresa A. Schlosser was Commander of ERDC, and Dr. David W. Pittman was the Director. 


\section{Acronyms and Abbreviations}

\begin{tabular}{|c|c|}
\hline CRREL & Cold Regions Research and Engineering Laboratory \\
\hline EASE & Equal-Area Scalable Earth \\
\hline ERDC & U.S. Army Engineer Research and Development Center \\
\hline GLDAS & Global Land Data Assimilation System \\
\hline MODIS & Moderate Resolution Imaging Spectroradiometer \\
\hline NASA & National Aeronautics and Space Administration \\
\hline NDSI & Normalized Difference Snow Index \\
\hline NOHRSC & National Operational Hydrologic Remote Sensing Center \\
\hline NSIDC & National Snow and Ice Data Center \\
\hline $\mathrm{PM}$ & Passive Microwave \\
\hline RMSE & Root-Mean-Square Error \\
\hline ROSES & Research Opportunities in Space and Earth Science \\
\hline RRB & Red River Basin \\
\hline SCA & Snow-Covered Area \\
\hline SDC & SWE Depletion Curve \\
\hline SNODAS & Snow Data Assimilation System \\
\hline $\mathrm{SSM} / \mathrm{I}$ & Special Sensor Microwave/Imager \\
\hline SSMIS & Special Sensor Microwave Imager/Sounder \\
\hline SWE & Snow Water Equivalent \\
\hline VIIRS & Visible Infrared Imaging Radiometer Suite \\
\hline
\end{tabular}




\section{Introduction}

\subsection{Background}

Annual snowpacks are fundamental in the northern hemisphere midlatitudes and mountain regions. They influence critical decisions regarding water resource management, flood control strategies, infrastructure development, and outdoor recreation and tourism. However, because snow has high spatial variability and often occurs in sparsely populated regions, monitoring snow has proven historically challenging. The advent of weather and defense satellites in the mid-twentieth century has greatly increased global snow-monitoring capabilities. In particular, beginning in the 1960s, satellites have proven effective at differentiating snow-covered and snow-free areas (e.g., Matson 1991). More recently, highly advanced polarorbiting satellites such as the Moderate Resolution Imaging Spectroradiometer (MODIS) and the Visible Infrared Imaging Radiometer Suite (VIIRS), launched in 2002 and 2011, respectively, have provided high-fidelity daily global snow-cover area (SCA) measurements at a greater than $1 \mathrm{~km}$ spatial resolution (e.g., MODIS: Hall et al. 2002; VIIRS: Key et al. 2013).

While satellites have proven highly effective at identifying snow cover, they are much less effective at measuring the amount of snow on the ground (i.e., the snow water equivalent [SWE]). Satellites that measure terrestrial microwave radiation (e.g., frequencies lower than $89 \mathrm{GHz}$ ) are sensitive to SWE. However, these observations are subject to large uncertainties due primarily to the complicated radiative properties of snow and to snow's interaction with the underlying terrain and overhead forest vegetation (e.g., Foster et al. 2005). The relatively high spatial variability of SWE as compared to the coarse $25 \times 25 \mathrm{~km}$ pixel size of most operational satellite-derived SWE products adds additional uncertainty.

Chang et al. (1982) described the first algorithm used to estimate SWE on a global scale using passive microwave (PM) satellite observations. It relies on an empirical formula applied to the brightness temperature difference between two onboard PM channels. Since Chang et al. (1982), numerous products providing gridded quantitative estimates of SWE based on PM satellite observations have been developed, each with their respective strengths and weaknesses (e.g., GlobSnow: Luojus et al. 2010, Takala et al. 2011; AMSR-E and AMSR2: Kelly 2009). These products are all largely 
based on the original Chang et al. (1982) algorithm but vary in their respective details. Importantly, these products do not always agree with each other and can differ by up to a factor of two for a given region, depending on snow quality and time of year (Mudryk et al. 2015; Cho et al. 2017). In particular, these data sets are highly uncertain during snowmelt due to the presence of liquid water in the snowpack (e.g., Ulaby et al. 1986; Kopczynski et al. 2008; Takala et al. 2011).

Other global and regional estimates of SWE are generated by merging different satellite observations, in situ measurements, numerical weatherprediction data, and static terrain data sets using data-assimilation techniques (e.g., The Global Land Data Assimilation System [GLDAS]: Rodell et al. 2004; SNODAS: Barrett 2003). However, these data are also subject to significant uncertainty.

\subsection{Objectives}

In this study, we aim to improve watershed-average SWE estimates by combining PM SWE observations with satellite-observed SCA. Specifically, we demonstrate that leveraging climatological relationships between PM SWE estimates developed using the Special Sensor Microwave/Imager (SSM/I) and Special Sensor Microwave Imager/Sounder (SSMIS) satellite sensors (Armstrong et al. 2016) and MODIS temporally averaged SCA (Morriss et al. 2016) improves daily-average SWE estimates during snowmelt.

\subsection{Approach}

We determine the relationship between SWE and SCA by broadly following the concept of the widely used "SWE depletion curve" (SDC) (Anderson 1973; Rango and Martinec 1982; Luce et al. 1999; Luce and Tarboton 2004). Typically, SDCs are used in conjunction with distributed energybalance models to reconstruct SWE for a specific watershed. However, the specific methods used to determine SDCs vary according to the application and desired outcome. For example, physically based statistical representations are often used for SDCs on the pixel scale (Luce and Tarboton 2004) while others use tuned empirical relationships to estimate SDCs over specific watersheds (e.g., Luce et al. 1999).

SDCs are particularly accurate in mountainous regions where, during the melt season, basin total SWE is strongly controlled by the static terrain such that SCA is an accurate predictor of total SWE (e.g., Kolberg and 
Gottschalk 2010). Less well known is how successfully these curves perform in regions with minimal terrain variability where snow cover and amount are much more strongly controlled by synoptic weather variability.

This study focuses on the Red River Basin (RRB) in the north-central United States (Figure 1). This region is characterized by generally flat terrain and sparse vegetation. It is also highly prone to springtime flooding due to rapid snowmelt and river ice jams (e.g., Stadnyk et al. 2016; Berghuijs et al. 2016). Climate change may be exacerbating these flooding events by increasing temperature and precipitation over the region (e.g., Melesse 2004; Hirsch and Ryberg 2012; Liu et al. 2017). Passive microwave SWE algorithms generally perform well in this region because of its mild terrain and sparse vegetation (Vuyovich et al. 2014; Cho et al. 2017). However, their performance is degraded during the spring when liquid water infiltrates the snowpack and impacts the microwave emission (e.g., Hallikainen et al. 1986).

Figure 1. Map of the continental United States with the inset showing the region surrounding the Red River Basin. Shading shows terrain elevation.

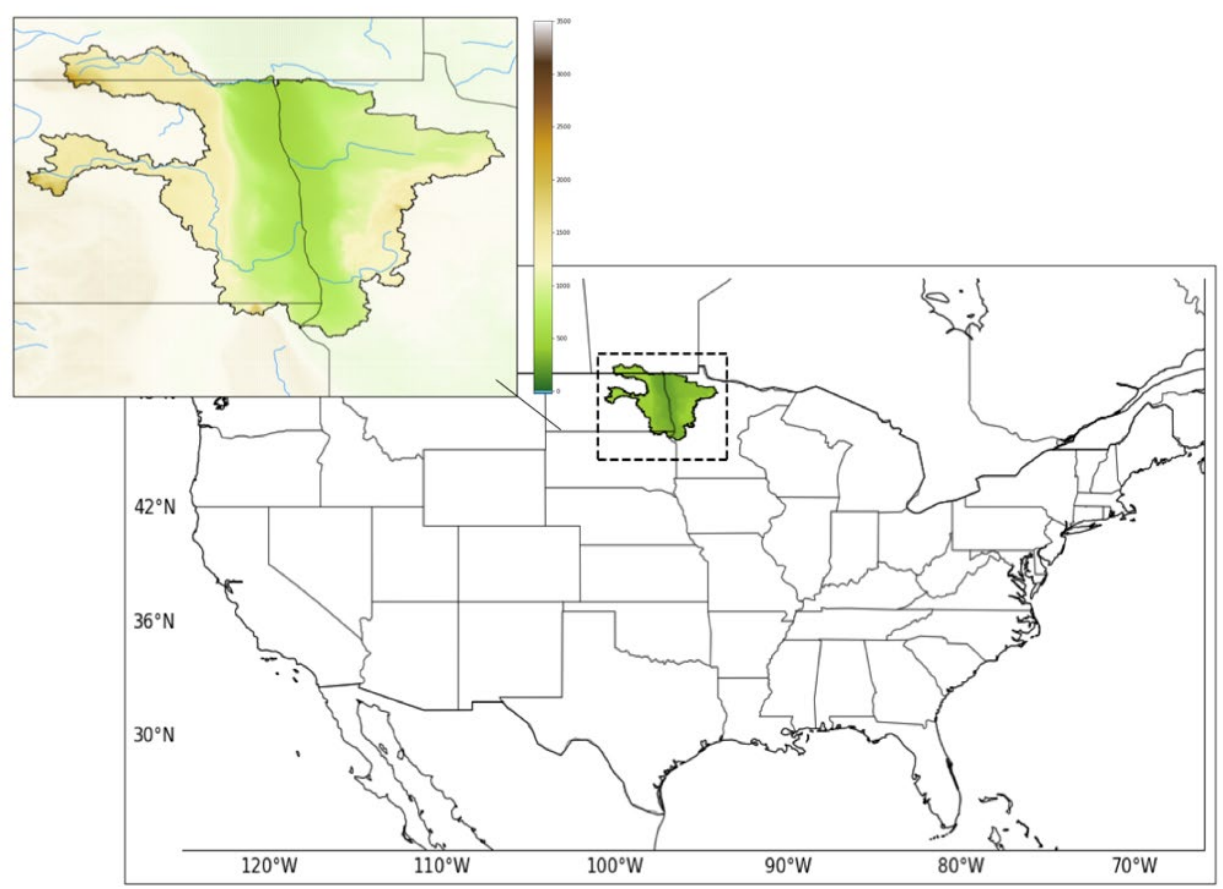

Therefore, section 2 presents the data and methodology, section 3 demonstrates improved capabilities, and section 4 presents conclusions and recommendations for future research and operational capabilities. 


\section{Data and Methods}

\subsection{MODIS cloud-gap-filled snow-covered area}

The MODIS daily SCA product is gridded at a $500 \mathrm{~m} \times 500 \mathrm{~m}$ resolution and uses the normalized difference snow index (NDSI) (Salomonson and Appel 2004) to map snow cover. MODIS data is projected onto a sinusoidal tile system that divides the globe into 460 separate tiles (Hall et al. 2002). One complicating aspect of the MODIS NDSI is that it is ineffective over cloudy pixels. This adds significant uncertainty when the RRB is partially snow covered.

In this analysis, we use a temporally filtered, "cloud-gap-filled" snow-cover product as an alternative to simply masking out cloudy pixels (Hall et al. 2010; Morriss et al. 2016). In this product, any MODIS pixel classified as cloudy for a given retrieval is filled with the most recently observed SCA value for the pixel. This product may introduce some bias into the analysis, particularly if the region is under prolonged cloud cover; however, this method substantially improves the daily SCA product and allows for a smoother transition during the melt season (Morriss et al. 2016).

\subsection{NSIDC snow water equivalent}

The National Snow and Ice Data Center (NSIDC) produces PM SWE data based on the algorithm developed by Armstrong and Brodzik (1995) and Brodzik (2014) (referred to as NSIDC for the remainder of this report) (M. Brodzik, NSIDC, pers. comm., March 2019). The NSIDC SWE data is gridded at a much coarser $25 \mathrm{~km} \times 25 \mathrm{~km}$ resolution on the Northern Equal-Area Scalable Earth (EASE) grid. This product retrieves SWE using an empirical relationship similar to the Chang et al. (1982) algorithm but recalibrated for the SSM/I and SSMIS satellite sensors. Because of size limitations in swath width over the midlatitudes, this product has periodic gaps in spatial coverage. These gaps affect the RRB approximately every 5 days. In this analysis, any day that has more than $20 \%$ of the basin affected by these gaps is discarded. 


\subsection{Snow-depletion-curve derivation}

In this subsection, we describe the derivation of the SDC used in this report. Here, a SWE depletion curve (SDC) is an empirically derived relationship between the NSIDC SWE $\left(S W E_{N S I D C}\right)$ and MODIS SCA, spatially averaged over the RRB during the melt season.

The melt season is defined as the period of time between the day of maximum basin average SWE ( $\left.t_{S W E \max }\right)$ and the day when SWE is totally depleted $\left(t_{S W E=0}\right)$. SWE estimated from an SDC is defined as

$$
S W E_{S D C}=f_{S D C}(S C A),
$$

where SCA is in percent, $S W E_{S D C}$ is the SWE estimated from the SDC, and $f_{S D C}$ is the empirically derived function. To account for the high interannual variability of SWE in the RRB (basin-mean maximum SWE can vary by over $100 \mathrm{~mm}$ annually), SWE is normalized by the annual basin-mean maximum SWE ( $S W E_{\max }$ ) following methods described in the literature (e.g., Luce et al. 1999):

$$
S W E_{S D C}^{*}=f_{S D C}^{*}(S C A),
$$

where $S W E_{S D C}^{*}=S W E / S W E_{\max }$ and $f_{S D C}^{*}$ is derived from normalized SWE values. To derive $f_{S D C}^{*}$, MODIS SCA and NSIDC SWE data are compiled for the 11-year period spanning water years 2008 through 2018.

The concept of an SDC is illustrated by plotting the RRB average $S W E_{N S I D C}^{*}$ against RRB average SCA for water year 2014 (Figure 2). Figure 2 shows that the seasonal coevolution of SWE and SCA follows a similar pattern as previous literature has identified (e.g., Luce and Tarboton 2004; Magand et al. 2014). In particular, there is a characteristic hysteresis whereby the basin-mean SCA saturates at low $S W E_{N S I D C}^{*}$ during the accumulation season (November-December), indicating that the entire basin is covered with shallow snow. SWE then accumulates throughout the midwinter (January-March) while SCA remains relatively unchanged. During the melt season (March-May), SWE $E_{N S I D C}^{*}$ and SCA decrease in tandem, indicative of a snow extent decreasing as the snow melts. 
Figure 2. SDC illustration. SCA scattered against $W$. Colors indicate date. The polynomial-fitted SDC is shown as a dashed line.

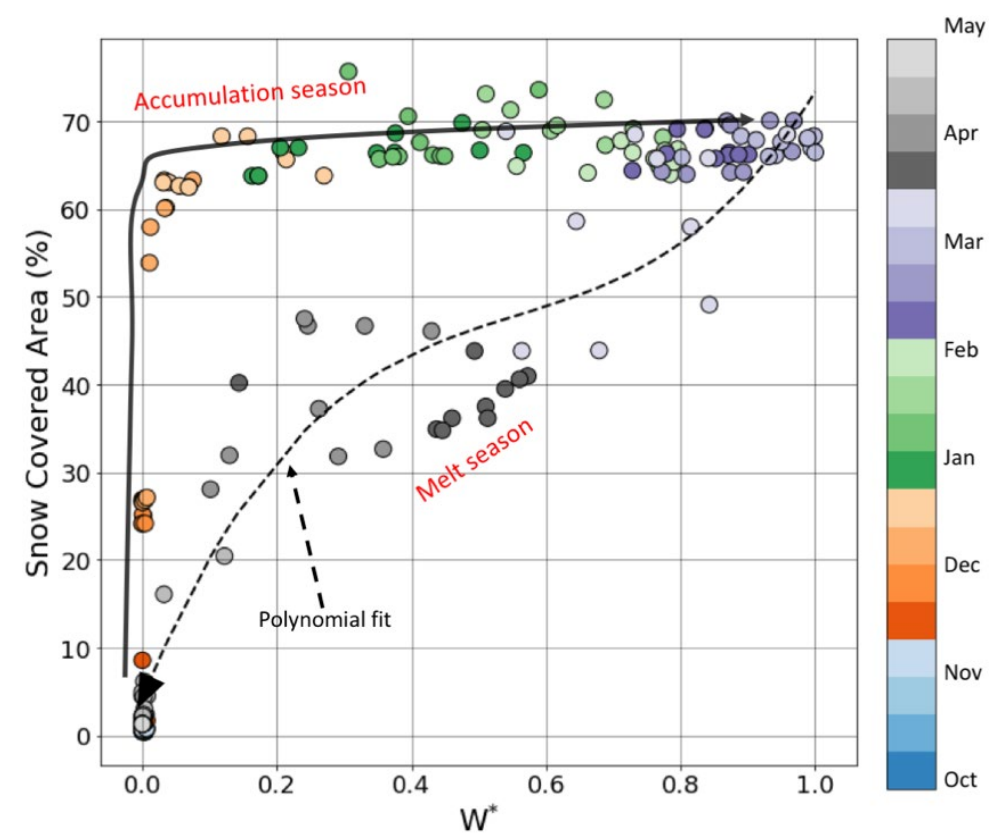

From Figure 2, one can infer that the SDC is best suited to the melt season when there is a clear relationship between basin-mean SCA and SWE. This is the relationship that determines the SDC. Our study generalizes this relationship by first restricting the SWE and SCA data sets to the melt season:

$$
t_{S W E_{\max , N S I D C}}<t<t_{S W E=0}
$$

Second, a simple third-order polynomial-fitting procedure is used to relate basin-mean $S W E^{*}$ and SCA:

$$
f_{S D C}^{*}(S C A)=a S C A^{3}+b S C A^{2}+c S C A+d,
$$

where $a, b, c, d$ are fitted coefficients. In this work, $a, b, c, d$ are computed separately for each melt season in the 11-year data set (e.g., Figure 2). Third, a single SDC is computed by averaging the coefficients from each individual year, referred to as climatological $a, b, c, d$ (Table 1). Figure 3 illustrates the SDCs for each year in addition to the average SDC.

Table 1. Coefficients for $f^{*}$ SDC $(S C A)$, representing an average of coefficients from 2007 to 2018.

\begin{tabular}{|c|c|c|c|}
\hline$a$ & $b$ & $c$ & $d$ \\
\hline$-2.51 \times 10^{-6}$ & $3.45 \times 10^{-4}$ & $-5.15 \times 10^{-5}$ & 0.0170 \\
\hline
\end{tabular}


Figure 3. Mean SDC (thick black line). Each dashed line corresponds to the SDC for an individual year. Point colors indicate the day of the melt season with cool colors indicating the beginning of snowmelt. SCA percent is the average over the RRB, and SWE* is the normalized SWE (SWE/SWE $\left.E_{\max }\right)$.

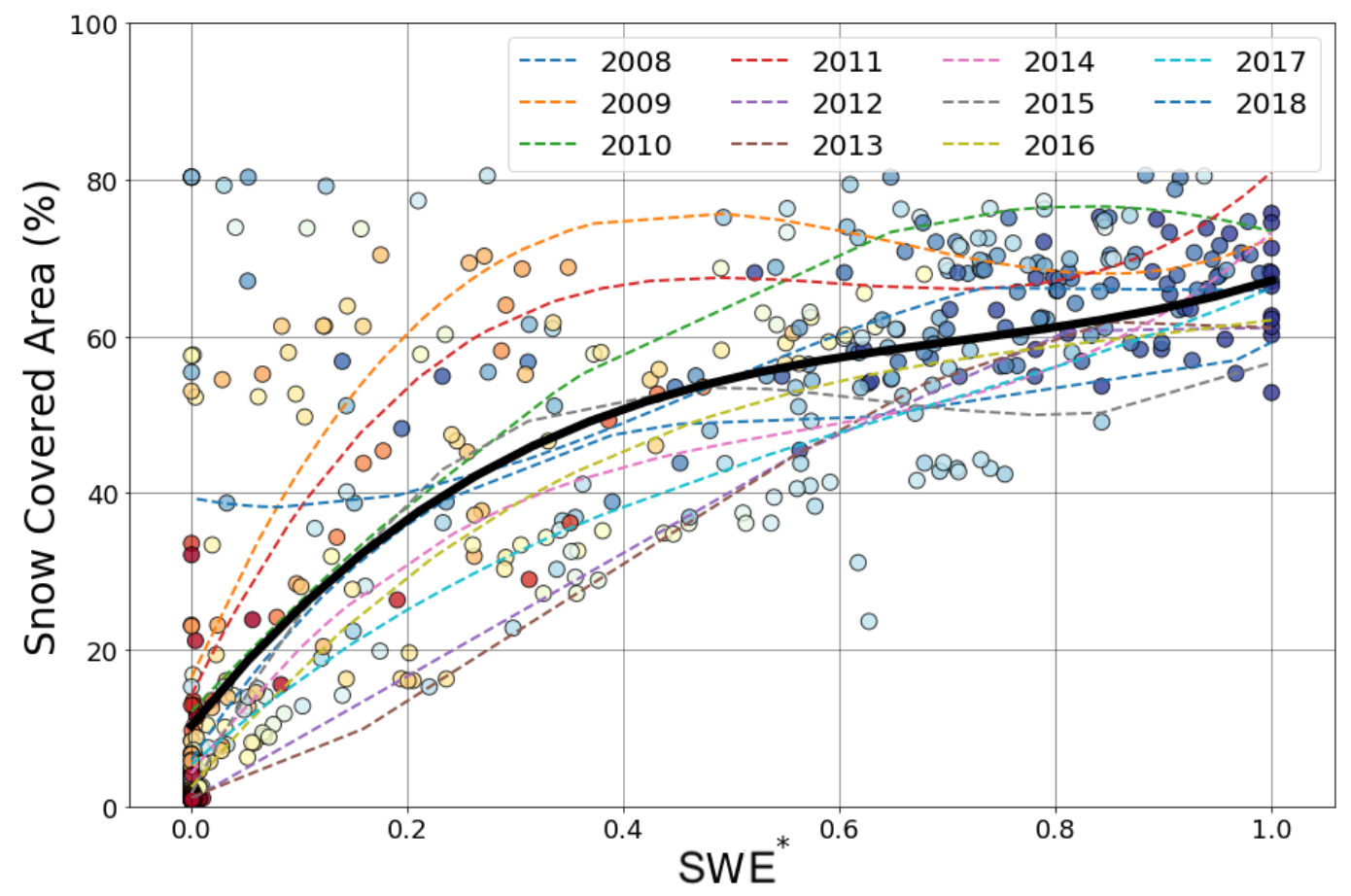

The coefficients in Table 1 are derived by averaging over the entire climatology and are provided for reference. It is important to note that the coefficients used in the SDC evaluation are slightly different due to the evaluation methodology described in the following subsection.

\subsection{Snow Data Assimilation System evaluation data set}

Evaluating the SDC is complicated by there being no ground truth SWE observations that accurately characterize SWE over the entire RRB. For example, there are no consistent daily in situ SWE observations within the RRB that span the 2007-2018 period. Additionally, available snow-depth observations from cooperative observation networks are biased towards higher population-density centers and are not reported daily.

Because of the dearth of high-quality ground truth data in the region, we chose to use the National Operational Hydrologic Remote Sensing Center (NOHRSC) Snow Data Assimilation System (SNODAS) product as our evaluation data set (Barnett 2003; National Operational Hydrologic Remote Sensing Center 2004). The aim of SNODAS is to provide a physically 
consistent product that assimilates data from satellites, aircraft measurements, and in situ observations into a spatially distributed energy-balance model forced with downscaled numerical weather-prediction data. It has a spatial resolution of $1 \mathrm{~km}^{2}$ and a daily temporal resolution. While this data set is a blended model/observation data set and not an actual observed snow state, it is likely the best estimate of SWE for 2007-2018 over the RRB due to the lack of accurate snow measurements in the region. However, it is important to consider that, since SNODAS is not an observation, it is subject to uncertainty associated with sparse observations, errors in NWP forcing, and unresolved model processes (e.g., Clow et al. 2012). Conveniently, because SNODAS is a gridded product, it is mappable to the same geographic constraints applied to the NSIDC SWE and MODIS SCA products, thereby eliminating the need to account for "unobserved" regions within the RRB in the evaluation.

Importantly, while the data assimilated into SNODAS does not include PM SWE observations, it does include satellite-derived SCA from MODIS. This assimilation creates a potential for bias in the following analysis, since the SDC is derived from MODIS SCA measurements. However, the MODIS SCA assimilation is not a traditional assimilation technique. Rather, the assimilation involves creating a binary "snow" versus "snow-free" mask from MODIS SCA that is used only to remove snow from SNODAS over pixels classified as snow free in MODIS and does not otherwise impact the SWE. Furthermore, the assimilation is performed manually using a cloudmasked product, further limiting the impact of these observations on the SNODAS SWE (Carrie Olheiser, National Oceanic and Atmospheric Administration, pers. comm., 2019). Finally, because of the other in situ SWE and snow-depth observations assimilated into SNODAS within the RRB, the impact of snow cover on SNODAS SWE is limited. Therefore, while we acknowledge the potential for limited bias, we expect it is small and that it does not strongly impact the conclusions of this work.

\subsection{Red River Basin data masking}

Prior to the derivation and evaluation of the SDC, the sinusoidal MODIS data, the EASE grid NSIDC data, and the SNODAS SWE data are interpolated to cylindrical latitude and longitude grids with comparable spatial resolutions for each product. Each data set is then subset to cover the RRB by masking all data points outside of the RRB as outlined by the U.S. Geological Survey North Dakota Water Science Center (Ryberg et al. 2016). 
Figure 4 presents examples of each of the previously discussed products with the applied RRB.

Figure 4. Comparison of NSIDC SWE (left), SNODAS SWE (center), and MODIS cloud-gap-filled SCA (right) from 10 March 2014.
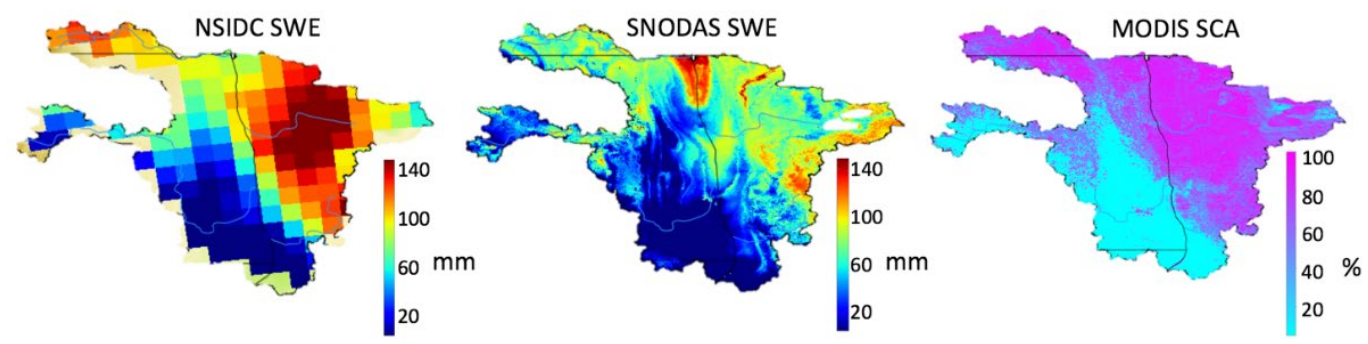

\subsection{Evaluation methodology}

The SDC evaluation is performed as follows: For each year in the data set, the climatological SDC is used to compute $S W E^{*}$ during the melt season. To ensure independence between $S W E^{*}$ from the climatological SDC for each year, the climatological SDC is computed using all years except the evaluation year. For example, when evaluating $S W E^{*}$ for water year 2014, data from water year 2014 is not included in the derivation of the climatological SDC. Note that this method results in fitted "climatological" coefficients that are slightly different for each analysis year. Once $S W E^{*}$ is determined for each day within the melt season, it is multiplied by the $S W E_{\max , N S I D C}$ to compute a time series of basin-mean SWE during the melt season $\left(S W E_{S D C}\right)$.

Once $S W E_{S D C}$ is computed, $S W E_{S N O D A S}$ is restricted to the melt season as determined by NSIDC $\left(t>t_{S W E_{\max , N S I D C}}\right)$ for each year and averaged over the RRB. The resultant melt-season time series of $S W E_{S N O D A S}, S W E_{S D C}$, and $S W E_{N S I D C}$ are aggregated over the 11-year data set and quantitatively assessed using root-mean-square error (RMSE), absolute percent bias, and least-squares linear regression. Bias is computed as follows:

$$
\text { bias }=\frac{\left|\sum S W E_{1}-S W E_{2}\right|}{S W E_{2}} \times 100 .
$$

Improvement is defined as decreases in RMSE and bias, coincident with increase in $r^{2}$ when comparing $S W E_{S N O D A S}$ to $S W E_{S D C}$ versus $S W E_{N S I D C}$. Qualitative assessments of individual water years are also performed to demonstrate structural improvements in basin-mean SWE time series. 


\subsection{SDC climatological size requirements}

We expand on the above methodology to determine how many years of SCA data are required to derive an SDC that generates more-accurate results than the stand-alone NSIDC SWE product. This analysis is performed by varying the number of years incorporated into the climatological SDC derivation and is described by the following steps: (1) A new "climatological" SDC is calculated 11 times, each one with a different number of years ( $n$, ranging $1-11)$ incorporated in its derivation:

$$
f_{S D C}^{*}(S C A)_{n}=\frac{\sum_{x=1}^{n} f_{S D C}^{*}(S C A)_{x}}{n},
$$

where $x$ represents a specific year in the data set. (2) Each of the 11 SDCs is used in place of the "climatological" SDC to compute $S W E_{S D C}$ over all 11 years in the data set, following the previously described methodology. For instance, if $n=2$, the SDC is derived from only 2 years of SCA data. This 2-year SDC is then used to estimate SWE for the entire 11-year period. (3) The statistical analysis described in the previous section comparing $S W E_{S D C}$ and $S W E_{N S I D C}$ to $S W E_{S N O D A S}$ is repeated for each SDC.

Importantly, steps $1-3$ are repeated 500 times while randomizing the specific years incorporated into each SDC derivation. The quantitative assessment is performed using the mean RMSE, $r^{2}$, and bias over the 500 samples determined through randomization. The randomization and repetition of steps 1-3 ensure that the results are not based on a particular year in the data set but rather are indicative of climatological data set size requirements.

\subsection{SDC spatial patterns}

To assess subbasin-scale improvement in SWE estimates using the SDC method (i.e., where within the basin the SDC yields the greatest improvement), the SDC is used to estimate SWE at each NSIDC pixel within the RRB. These pixel $S W E_{S D C}$ values are then evaluated against SNODAS and compared against the NSIDC as described in section 2.6.

To perform this analysis, the daily MODIS SCA and SNODAS SWE data are first resampled to the NSIDC resolution by computing an average of all the MODIS and SNODAS pixels contained within each NSIDC pixel, thereby providing spatially consistent time-series data for all three data 
sets on the NSIDC SWE grid. The climatological RRB-averaged SDC (i.e., the Table 1 coefficients) is then used to compute $S W E_{S D C}^{*}$ at each NSIDC pixel from the pixel-mean SCA. Importantly, while the basin-mean SDC coefficients are used to compute $S W E_{S D C}^{*}$, when computing $S W E_{S D C}$ from $S W E_{S D C}^{*}$ at each pixel, the pixel $S W E_{\max }$ is used. Finally, pixel improvement is quantified using RMSE, bias, and $r^{2}$ following the methods from section 2.6. 


\section{Results}

\subsection{Qualitative assessment of SWE $S D C$}

Figure 5 presents time series comparing $S W E_{S N O D A S}$ to the $S W E_{N S I D C}$ and $S W E_{S D C}$ for each water year in the analysis. For nearly every water year, the SDC-derived SWE shows substantial improvement in basin-mean SWE over $S W E_{N S I D C}$. For example, in water years 2011, 2014, 2017, and 2018, $S W E_{S D C}$ shows persistence in the basin-mean SWE that closely matches $S W E_{S N O D A S}$ well after $S W E_{N S I D C}$ indicated no snow in the RRB. A brief analysis of surface weather maps for these years (Weather Prediction Center 2006) indicates that in each case the premature loss of SWE seen in the $S W E_{N S I D C}$ product occurred during the approximate onset of abovefreezing surface air temperatures within the basin and is therefore likely associated with melting snow. Additionally, in water year 2014, $S W E_{S D C}$ was able to capture a late season snow event that occurred during the melt season but that was not detected in the $S W E_{N S I D C}$ product. There is also evidence in Figure 5 that the SDC method reduces spurious detection of SWE from poor satellite retrievals. This is apparent in the time series of water year 2009. In this time series, there is a spurious detection of snow in $S W E_{N S I D C}$ that occurs during late April through mid-May. The time series of $S W E_{S D C}$ and $S W E_{S N O D A S}$ do not reproduce this feature. Finally, in all panels, $S W E_{S D C}$ shows a reduction in the daily noise evident in the $S W E_{N S I D C}$ time series associated with data gaps and poor retrievals. This analysis suggests that the SDC can improve basin-mean SWE estimates detecting snowpack persistence during active melting periods, reducing false alarms and eliminating daily noise in the NSIDC product. 
Figure 5. Time series showing $S W E_{S D C}, S W E_{N S I D C}$, and $S W E_{S N O D A S}$ from the date of max SWE to 31 May for each of the 11 water years in the data set.
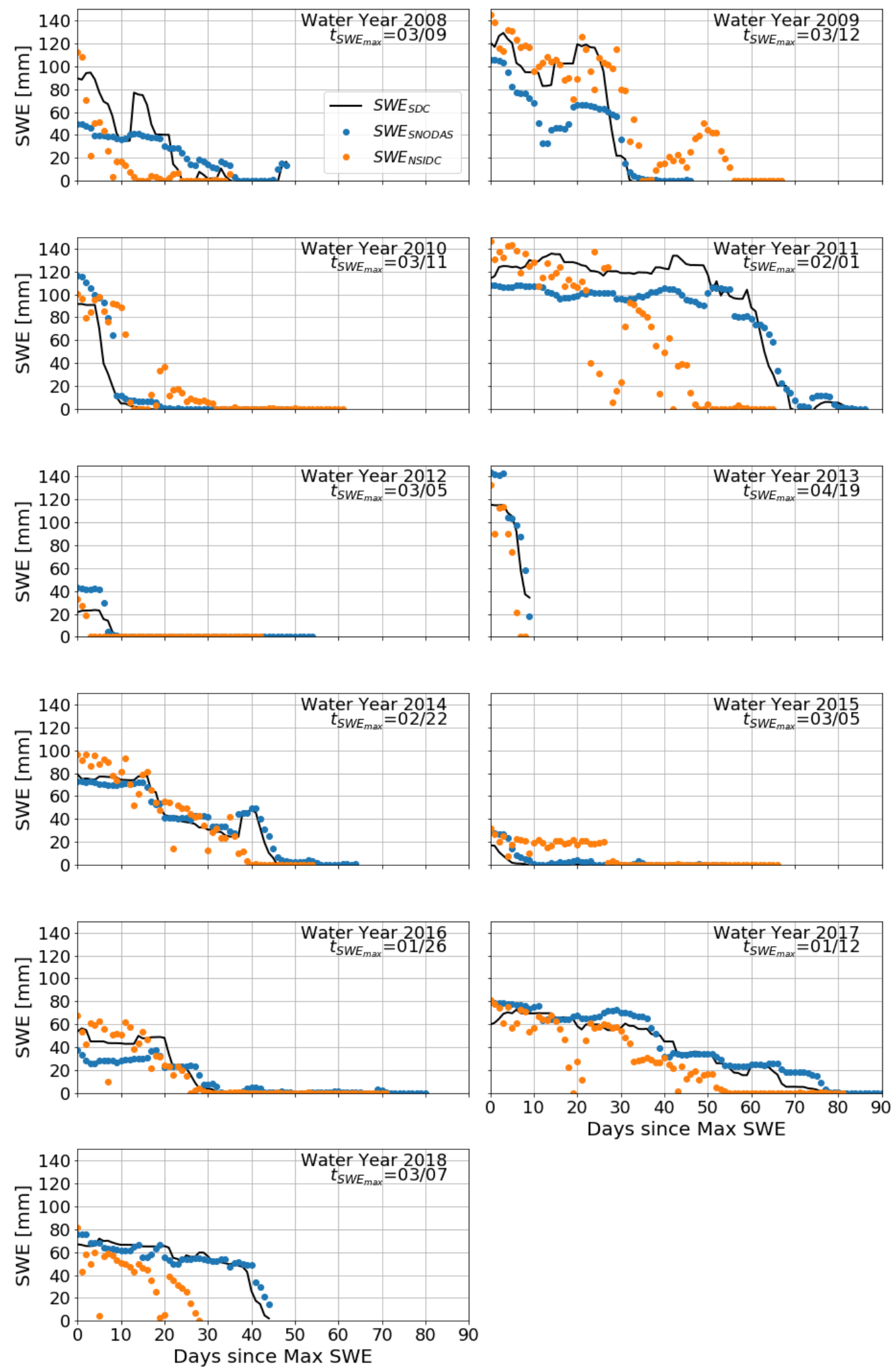


\subsection{Bulk quantitative analysis}

We quantify $S W E_{S D C}$ improvements by performing a bulk statistical analysis on all of the data over all years, following the methodology described in section 2. To assess improvement, we compute statistics to compare $S W E_{S D C}$ and $S W E_{N S I D C}$ each to $S W E_{S N O D A S}$.

This analysis indicates that $S W E_{S D C}$ shows statistical improvement over $S W E_{N S I D C}$ against $S W E_{S N O D A S}$ by all metrics. The RMSE is reduced by over a factor of two from $30.01 \mathrm{~mm}$ to $14.75 \mathrm{~mm}$, and $r^{2}$ increased from 0.50 to o.89. Finally, the absolute percent bias is reduced from $15 \%$ to $5 \%$. These bulk improvements are illustrated by comparing scatter plots of $S W E_{S D C}$ and $S W E_{N S I D C}$ against $S W E_{S N O D A S}$ (Figure 6). While both $S W E_{S D C}$ and $S W E_{N S I D C}$ generally show a one-to-one relationship against $S W E_{S N O D A S}$, this figure emphasizes the improvement gained from the SDC by showing a reduced spread in the data (e.g., for $S W E_{S N O D A S} \approx 100, S W E_{N S I D C}$ ranges from o to 140, whereas $S W E_{S D C}$ is between 90 and 130) and a near elimination of false alarms and missed detections (i.e., points falling along the $\mathrm{x}$ - and y-axes).

Interestingly, the spread between $S W E_{S D C}$ and $S W E_{S N O D A S}$ remains relatively high for intermediate values of SWE, suggesting that the climatological SDC has greater uncertainty during the height of the melt season. Further investigation of the time series in Figure 5 indicates this increased spread is largely due to apparent poor SDC performance in 2008 and 2009. This apparent poor performance can be partially linked to the $S W E_{\max , N S I D C}$ and $S W E_{\max , S N O D A S}$ in 2008 and 2009 being substantially different from one another, and thus the performance of the SDC was proportional to this difference. Estimating $S W E_{S D C}$ following $S W E_{S D C}$ $=S W E_{S D C}^{*}\left(S W E_{\max , S N O D A S}\right)$ instead of $S W E_{S D C}=S W E_{S D C}^{*}\left(S W E_{\max , N S I D C}\right)$ largely eliminates the intermediate range spread; however, it is difficult to draw more general conclusions in this instance since $S W E_{\max , N S I D C}$ and $S W E_{\text {max }, S N O D A S}$ were in close agreement in most years. 
Figure 6. Scatter-plot comparison of $S W E_{N S I D C}$ vs. $S W E_{S N O D A S}$ (bottom) and $S W E_{S D C}$ vs. SWESNODAS (top). The black dashed lines show the one-to-one relationship in each figure.
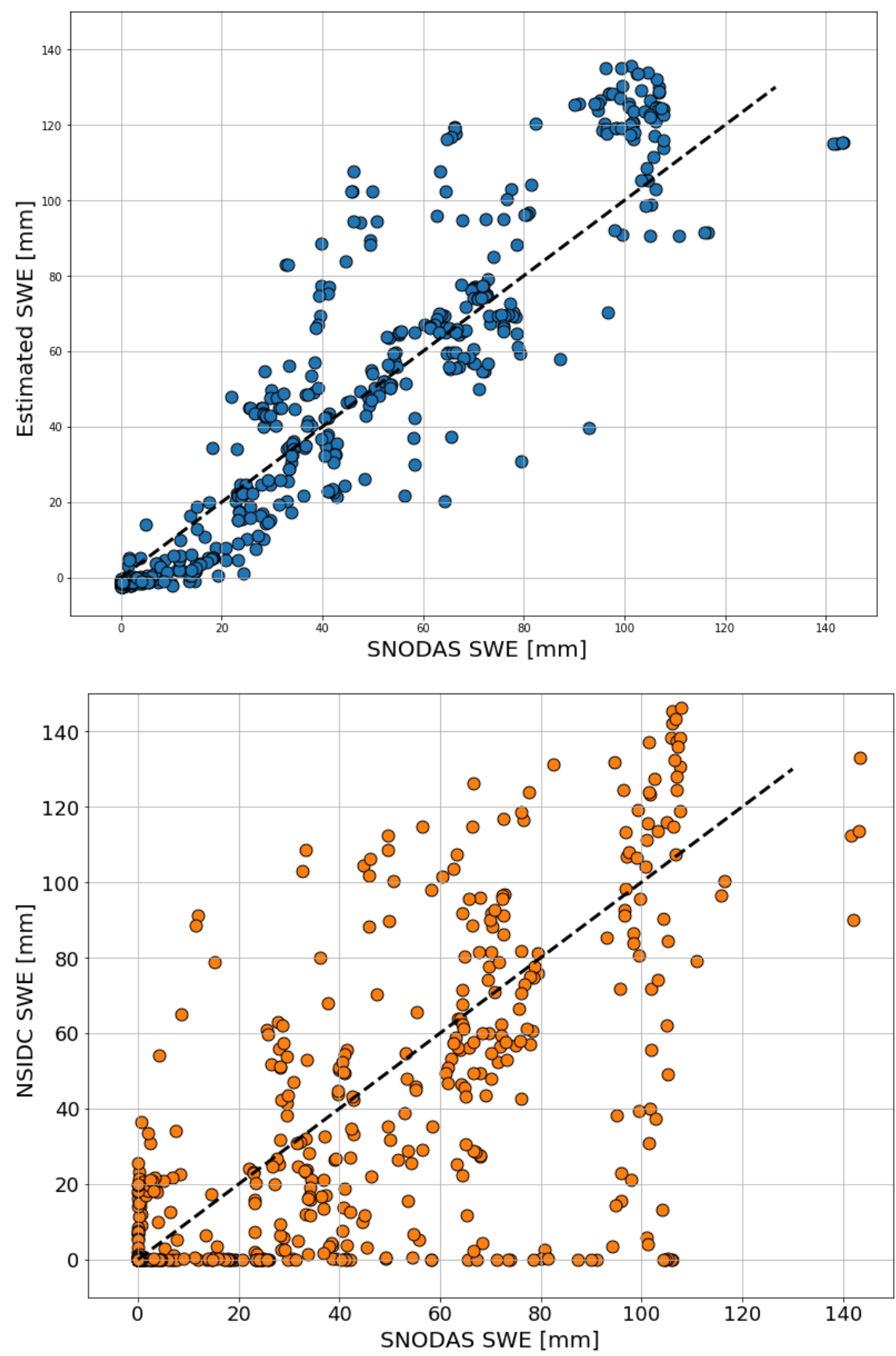

\subsection{SDC climatological size requirements analysis}

Expanding on the statistical analysis in section 3.2, we explored the number of years required in the SDC derivation data set to gain improvement over NSIDC according to the methods outlined in section 2.7. 
Figure 7 plots RMSE, percent bias, and $r^{2}$ as a function of climatology size. As expected, these metrics improve as more years are added to the data set. While RMSE shows nearly linear improvement, improvements in bias and $r^{2}$ accelerate once the data set spans 8 years. In comparing the results shown in Figure 7 to the RMSE, percent bias, and $r^{2}$ between the baseline $S W E_{N S I D C}$ and $S W E_{S N O D A S}$, one concludes that at least 10 years are required in the climatology that determines $f_{S D C}^{*}(S C A)$ before $S W E_{S D C}$ outperforms $S W E_{N S I D C}$ as determined by the statistical metrics (section 2.6). It is likely that including more years in the data set will lead to slightly more accurate results, but it is unclear from this analysis what the maximum potential improvement is.

Figure 7. RMSE (top), percent bias (middle), and $r^{2}$ (bottom) as a function of years in the SDC data set.
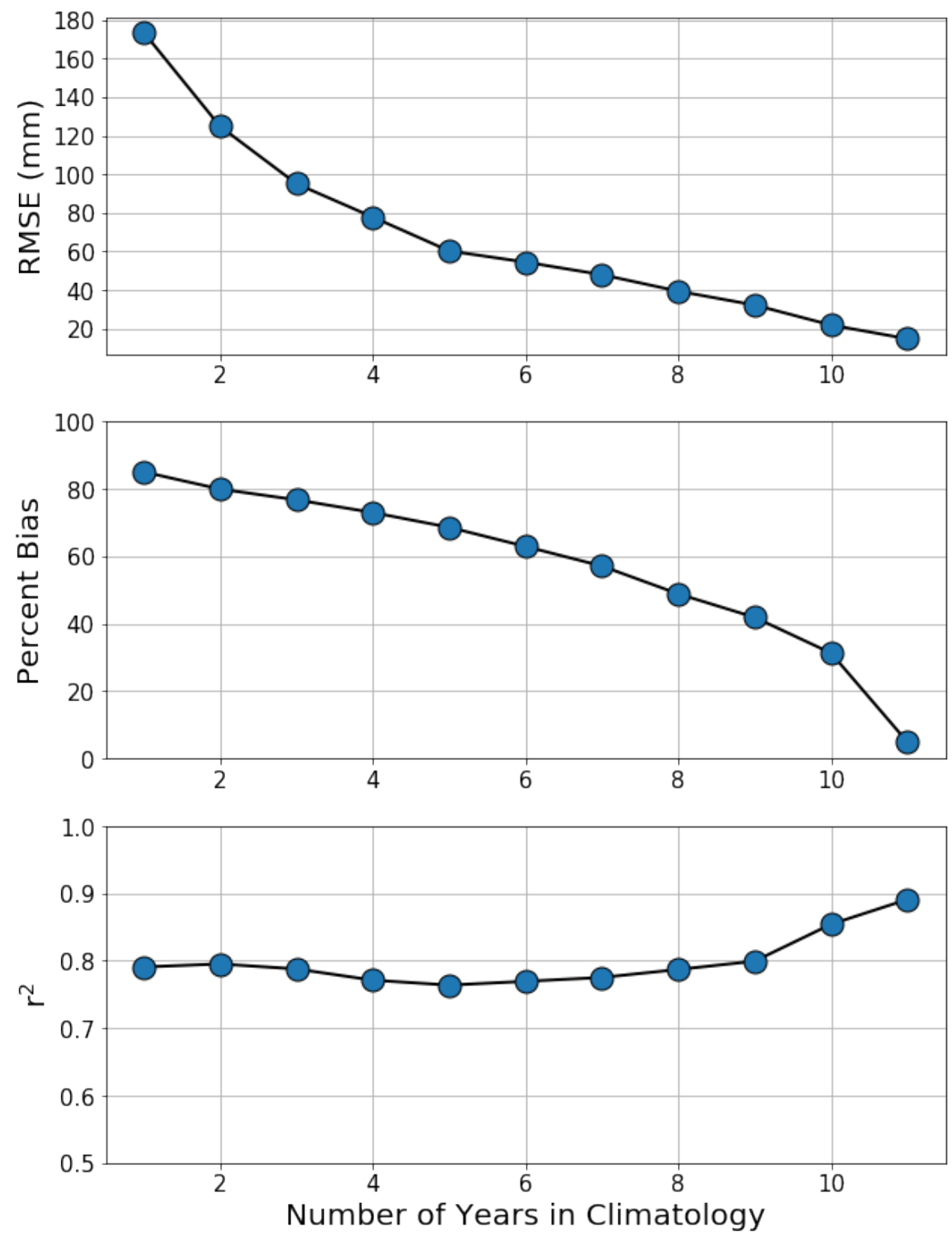


\subsection{Subbasin statistical analysis}

Finally, to gain insight into the subbasin-scale properties of the SDC, the analysis (section 2) is performed for each NSIDC $25 \mathrm{~km}^{2}$ SWE pixel separately within the RRB. RMSE, bias, and $r^{2}$ are then plotted geographically, illuminating spatial patterns in $S W E_{N S I D C}$ and $S W E_{S D C}$ performance (Figure 8).

Figure 8. $S W E_{N S I D C}$ vs. $S W E_{S N O D A S}$ (left) and $S W E_{S D C}$ vs. $S W E_{S N O D A S}$ (right). In all figures, warm colors indicate more accurate results than cool colors.
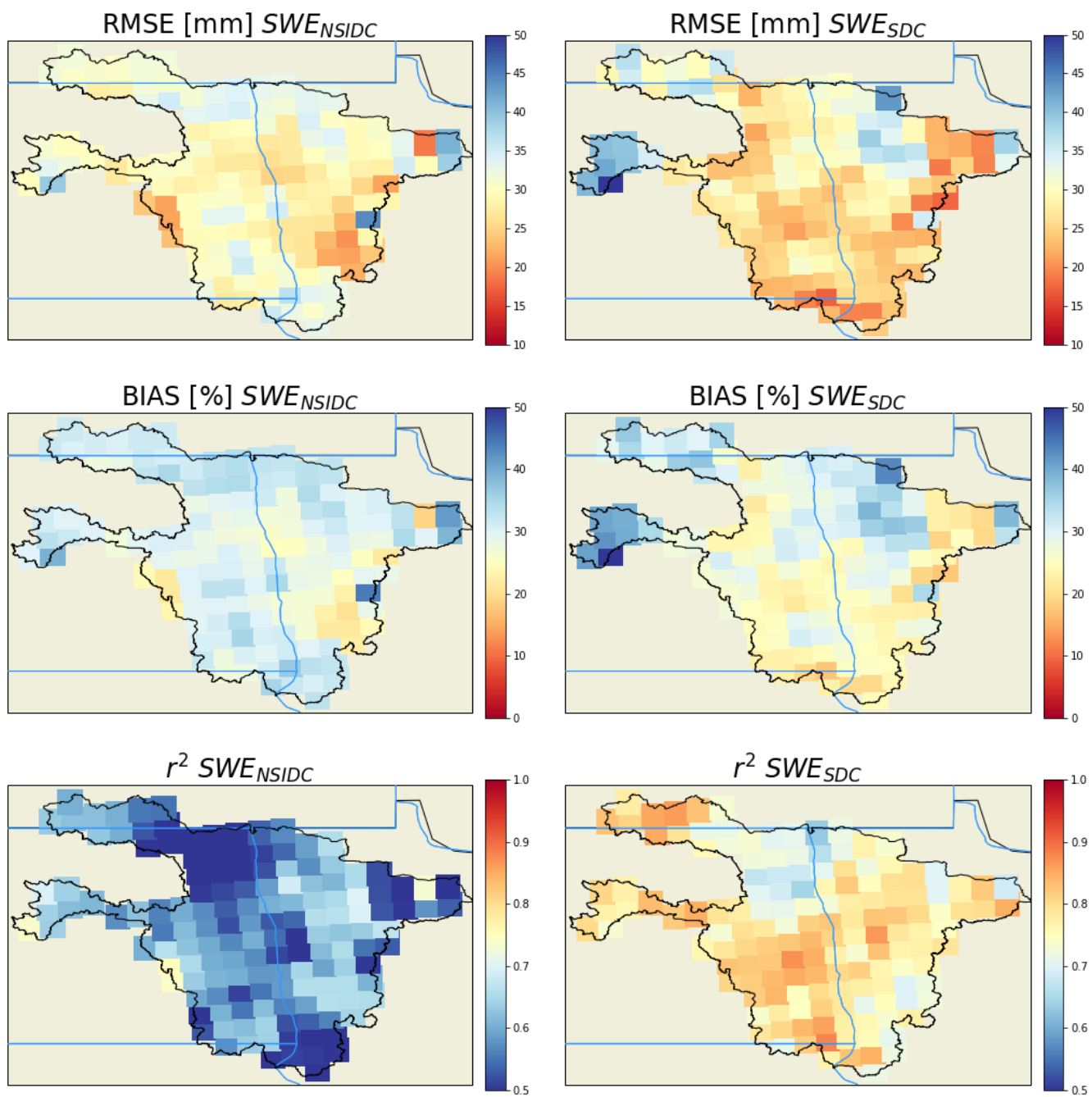

In general, the RMSE is lowest over the west-central part of the RRB region with higher RMSE in the northeast part of the domain where the region is forested. The SDC generally reduces the RMSE broadly over the region. There is substantial improvement in the southern part of the RRB where snowmelt will most likely have the strongest impact on the PM SWE 
retrieval. Percent bias shows a similar pattern with a general decrease in bias throughout the bulk of the region with the largest gains in the southern part of the basin. The SDC systematically improves $r^{2}$ over the entire RRB. This is almost certainly due to a reduction of false and missed SWE detections inherent in the $S W E_{N S I D C}$ product that have an outsized impact on the least-squares methodology used to calculate $r^{2}$. However, $r^{2}$ improvement over the south-central RRB is coincident with the RMSE and bias improvements and is further indication that the SDC can mitigate suspect $S W E_{N S I D C}$ values due to snowmelt.

In some locations, the SDC actually degrades the SWE estimates as compared to the baseline $S W E_{N S I D C}$ product. For example, $S W E_{S D C}$ has a higher RMSE and bias over the western extensions of the RRB through North Dakota. While it is difficult to ascertain the exact causes for this apparent degradation, we speculate that these extensions are sufficiently small and geographically distinct as compared to the overall RRB such that the basin-mean SDC used to relate SCA to SWE is not wholly representative of these geographic appendages. This implies that the SDC discussed in this study is specific to the RRB region and would likely fail to represent SWE accurately elsewhere. 


\section{Conclusions}

The results presented in this study illustrate that combining the climatologically accurate NSIDC snow water equivalent (SWE) product with the more reliable and higher-resolution MODIS snow-covered area (SCA) product can substantially improve daily SWE estimates averaged over the Red River Basin (RRB) in the north-central United States. Critically, we demonstrated that a climatologically derived snow depletion curve (SDC) can consistently correct single-day or seasonal errors in the NSIDC SWE product during the melt season.

Furthermore, we showed that the 11-year climatology used in this study was sufficient to provide substantial improvement over the NSIDC product alone when compared to SNODAS. This suggests that this product, with the coefficients presented in Table 1, can be used as a standalone daily SWE estimate during the critical melt season and provide a more accurate SWE estimate during days in which the NSIDC SWE product is suspect. Importantly, this can be used to identify rapid melt events (i.e., rapid losses of SWE over the RRB) that may have otherwise been missed in NSIDC due to liquid water in the snowpack and prevent false detection of rapid melt events.

Finally, this algorithm, in combination with other developmental algorithms based on PM observations, could potentially aid forecasters in identifying melting snowpacks by monitoring discrepancies between the SDC-estimated SWE and the NSIDC SWE throughout the spring months. 


\section{References}

Anderson, E. A. 1973. National Weather Service River Forecast System-Snow Accumulation and Ablation Model. NOAA Technical Memorandum NWS HYDRO-17. Silver Spring, MD: U.S. Department of Commerce.

Armstrong, R., K. Knowles, M. Brodzik, and M. A. Hardman. 2016. DMSP SSM/I-SSMIS Pathfinder Daily EASE-Grid Brightness Temperatures, Version 2. Boulder, CO: National Snow and Ice Data Center, Distributed Active Archive Center. https://nsidc.org/data/NSIDC-0032/versions/2.

Armstrong, R. L., and M. J. Brodzik. 1995. "An Earth-Gridded SSM/I Data Set for Cryospheric Studies and Global Change Monitoring." Advances in Space Research 16 (10): 155-163.

Barrett, A. P. 2003. National Operational Hydrologic Remote Sensing Center Snow Data Assimilation System (SNODAS) Products at NSIDC. Special Report \#11. Boulder, CO: National Snow and Ice Data Center, Cooperative Institute for Research in Environmental Sciences. https://nsidc.org/sites/nsidc.org/files/files $\angle$ nsidc_special_report_11.pdf.

Berghuijs, W. R., R. A. Woods, C. J. Hutton, and M. Sivapalan. 2016. "Dominant Flood Generating Mechanisms Across the United States." Geophysical Research Letters 43 (9): 4382-4390.

Brodzik, M. J. 2014. F17vs. F13 SWE Regression. Last modified 20 January 2014. http://cires1.colorado.edu/ brodzik/F13-F17swe/.

Chang, A. T. C., J. L. Foster, D. K. Hall, A. Rango, and B. K. Hartline. 1982. "Snow Water Equivalent Estimation by Microwave Radiometry.” Cold Regions Science and Technology 5 (3): 259-267.

Cho, E., S. E. Tuttle, and J. M. Jacobs. 2017. "Evaluating Consistency of Snow Water Equivalent Retrievals from Passive Microwave Sensors over the North Central US: SSM/I vs. SSMIS and AMSR-E vs. AMSR2.” Remote Sensing 9 (5): 465. https://doi.org/10.3390/rs9050465.

Clow, D. W., L. Nanus, K. L. Verdin, and J. Schmidt. 2012. "Evaluation of SNODAS Snow Depth and Snow Water Equivalent Estimates for the Colorado Rocky Mountains, USA.” Hydrological Processes 26 (17): 2583-2591.

Foster, J. L., C. Sun, J. P. Walker, R. Kelly, A. Chang, J. Dong, and H. Powell. 2005. "Quantifying the Uncertainty in Passive Microwave Snow Water Equivalent Observations." Remote Sensing of Environment 94 (2): 187-203. https://doi.org/10.1016/i.rse.2004.09.012.

Hall, D. K., G. A. Riggs, J. L. Foster, and S. V. Kumar. 2010. "Development and Evaluation of a Cloud-Gap-Filled MODIS Daily Snow-Cover Product." Remote Sensing of Environment 114 (3): 496-503. 
Hall, D. K., G. A. Riggs, V. V. Salomonson, N.E. DiGirolamo, and K. J. Bayr. 2002. "MODIS Snow-Cover Products." Remote Sensing of Environment 83 (1-2): 181-194.

Hallikainen, M., F. Ulaby, and M. Abdelrazik. 1986. "Dielectric Properties of Snow in the 3 to $37 \mathrm{GHz}$ Range." IEEE transactions on Antennas and Propagation 34 (11): $1329-1340$.

Hirsch, R. M., and K. R. Ryberg. 2012. "Has the Magnitude of Floods Across the USA Changed with Global $\mathrm{CO}_{2}$ levels?” Hydrological Sciences Journal 57 (1): 1-9.

Kelly, R. 2009. "The AMSR-E Snow Depth Algorithm: Description and Initial Results." Journal of the Remote Sensing Society of Japan 29:307-317.

Key, J. R., R. Mahoney, Y. Liu, P. Romanov, M. Tschudi, I. Appel, J. Maslanik, D. Baldwin, X. Wang, and P. Meade. 2013. "Snow and Ice Products from Suomi NPP VIIRS.” Journal of Geophysical Research: Atmospheres 118 (23): 12,816-12,830.

Kolberg, S., and L. Gottschalk. 2010. "Interannual Stability of Grid Cell Snow Depletion Curves as Estimated from MODIS Images.” Water Resources Research 46 (11). https://doi.org/10.1029/2008WR007617.

Kopczynski, S., J. Ramage, D. Lawson, S. Goetz, E. Evenson, J. Denner, and G. Larson. 2008. "Passive Microwave (SSM/I) Satellite Predictions of Valley Glacier Hydrology, Matanuska Glacier, Alaska.” Geophysical Research Letters 35 (16). https://doi.org/10.1029/2008GL034615.

Liu, C., K. Ikeda, R. Rasmussen, M. Barlage, A. J. Newman, A. F. Prein, F. Chen, L. Chen, M. Clark, A. Dai, J. Dudhia, T. Eidhammer, D. Gochis, E. Gutmann, S. Kurkute, Y. Li, G. Thompson, and D. Yates. 2017. "Continental-Scale ConvectionPermitting Modeling of the Current and Future Climate of North America." Climate Dynamics 49 (1-2): 71-95.

Luce, C. H., and D. G. Tarboton. 2004. "The Application of Depletion Curves for Parameterization of Subgrid Variability of Snow.” Hydrological Processes 18 (8): 1409-1422.

Luce, C. H., D. G. Tarboton, and K. R. Cooley. 1999. "Sub-Grid Parameterization of Snow Distribution for an Energy and Mass Balance Snow Cover Model." Hydrological Processes 13 (12-13): 1921-1933.

Luojus, K., J. Pulliainen, M. Takala, J. Lemmetyinen, C. Derksen, and L. Wang. 2010. Snow Water Equivalent (SWE) Product Guide. Global Snow Monitoring for Climate Research.

Magand, C., A. Ducharne, N. Le Moine, and S. Gascoin. 2014. "Introducing Hysteresis in Snow Depletion Curves to Improve the Water Budget of a Land Surface Model in an Alpine Catchment." Journal of Hydrometeorology 15 (2): 631-649.

Matson, M. 1991. "NOAA Satellite Snow Cover Data." Global and Planetary Change 4 (13): $213-218$. 
Melesse, A. M. 2004. "Spatiotemporal Dynamics of Land Surface Parameters in the Red River of the North Basin." Physics and Chemistry of the Earth, Parts $A / B / C 29$ (11-12): 795-810. https://doi.org/10.1016/j.pce.2004.05.007.

Morriss, B. F., E. Ochs, E. J. Deeb, S. D. Newman, S. F. Daly, and J. J. Gagnon. 2016. "Persistence-Based Temporal Filtering for MODIS Snow Products." Remote Sensing of Environment 175: 130-137.

Mudryk, L. R., C. Derksen, P. J. Kushner, and R. Brown. 2015. "Characterization of Northern Hemisphere Snow Water Equivalent Datasets, 1981-2010.” Journal of Climate 28 (20): 8037-8051.

National Operational Hydrologic Remote Sensing Center. 2004. Snow Data Assimilation System (SNODAS) Data Products at NSIDC, Version 1. [Masked Subset]. Boulder, CO: National Snow and Ice Data Center. Accessed October 2018. https://doi.org/10.7265/N5TB14TC.

Rango, A., and J. Martinec. 1982. "Snow Accumulation Derived from Modified Depletion Curves of Snow Coverage.” In Hydrological Aspects of Alpine and High Mountain Areas, Proceedings of the Exeter Symposium, July 1982. IAHS Publication No. 138. Oxfordshire, UK: International Association of Hydrological Sciences.

Rodell, M., P. R. Houser, U. E. A. Jambor, J. Gottschalck, K. Mitchell, C.-J. Meng, K. Arsenault, B. Cosgrove, J. Radakovich, M. Bosilovich, and J. K. Entin. 2004. "The Global Land Data Assimilation System." Bulletin of the American Meteorological Society 85:381-394.

Ryberg, K. R., J. A. Falcone, and K. A. Kolars. 2016. Total Phosphorus Load and Ancillary Data Related to Sources of Total Phosphorus in the Red River of the North Basin-Data Supporting Structural Equation Modeling of Total Phosphorus Loads. U.S. Geological Survey data release. U.S. Geological Survey. http://dx.doi.org/10.5066/F79G5JWD.

Salomonson, V. V., and I. Appel. 2004. "Estimating Fractional Snow Cover from MODIS Using the Normalized Difference Snow Index.” Remote Sensing of Environment 89 (3): $351-360$.

Stadnyk, T., K. Dow, L. Wazney, and E.-L. Blais. 2016. "The 2011 Flood Event in the Red River Basin: Causes, Assessment and Damages." Canadian Water Resources Journal/Revue canadienne des ressources hydriques 41 (1-2): 65-73.

Takala, M., K. Luojus, J. Pulliainen, C. Derksen, J. Lemmetyinen, J. P. Kärnä, J. Koskinen, and B. Bojkov. 2011. "Estimating Northern Hemisphere Snow Water Equivalent for Climate Research through Assimilation of Space-Borne Radiometer Data and Ground-Based Measurements." Remote Sensing of Environment 115:3517-3529.

Ulaby, F. T., R. K. Morre, and A. K. Fung. 1986. Microwave Remote Sensing: Active and Passive. Volume 3. From Theory to Applications. Reading, MA: Addison-Weslet Publishing Company. 
Vuyovich, C. M., J. M. Jacobs, and S. F. Daly. 2014. "Comparison of Passive Microwave and Modeled Estimates of Total Watershed SWE in the Continental United States." Water Resources Research 50 (11): 9088-9102.

Weather Prediction Center. 2006. WPC's Surface Analysis Archive. College Park, MD: National Oceanic and Atmospheric Association, National Weather Service, Weather Prediction Center. Accessed January 2019.

https://www.wpc.ncep.noaa.gov/archives/web_pages/sfc/sfc_archive.php. 


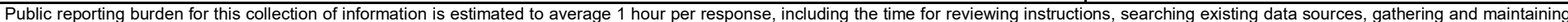

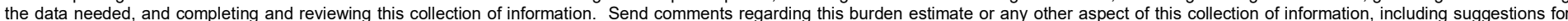

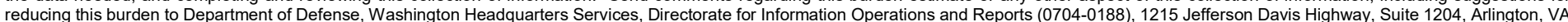

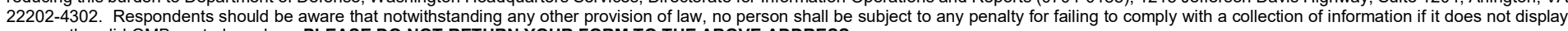
a currently valid OMB control number. PLEASE DO NOT RETURN YOUR FORM TO THE ABOVE ADDRESS.
1. REPORT DATE (DD-MM-YYYY)
December 2019

\section{TITLE AND SUBTITLE}

Improving Snow Estimates over the Red River Basin during the Spring Using Empirical

Relationships Between Satellite Snow Water Equivalent and Snow-Covered Area
3. DATES COVERED (From - To) FY2018-2019

5a. CONTRACT NUMBER

5b. GRANT NUMBER

5c. PROGRAM ELEMENT NUMBER

5d. PROJECT NUMBER

5e. TASK NUMBER

5f. WORK UNIT NUMBER

8. PERFORMING ORGANIZATION REPORT NUMBER

ERDC/CRREL TR-19-25

Army Engineer Research and Development Center (ERDC)

Cold Regions Research and Engineering Laboratory (CRREL)

72 Lyme Road

Hanover, NH 03755-1290

9. SPONSORING / MONITORING AGENCY NAME(S) AND ADDRESS(ES)

National Aeronautics and Space Administration (NASA)

NASA Headquarters

300 E. Street SW, Suite 5R30

Washington, DC 20546

10. SPONSOR/MONITOR'S ACRONYM(S)

NASA

11. SPONSOR/MONITOR'S REPORT NUMBER(S)

\section{DISTRIBUTION / AVAILABILITY STATEMENT}

Approved for public release; distribution is unlimited.

\section{SUPPLEMENTARY NOTES}

Funding provided by MIPR 80HQTR18T0049

\section{ABSTRACT}

Assessing rapid changes in snow storage during spring is critical for predicting river flooding along the Red River in the north-central United States. While passive microwave retrievals of snow water equivalent (SWE) over the Red River water basin are generally accurate, they are less certain during the spring due to snowmelt events. These degrade the SWE retrieval algorithms by introducing liquid water into the snowpack. To increase confidence in daily SWE estimates over the Red River basin, we use the concept of a SWE depletion curve to relate basin mean SWE to snow-covered area (SCA) as determined by the MODIS cloud-gap-filled daily SCA product. We use this concept to derive an empirical relation-ship between SWE and SCA over the Red River basin from 11 years of satellite observations (2007-2018). This relationship relies on the climatologically accurate passive microwave SWE product to mitigate acute inaccuracies in daily SWE retrievals caused by data gaps and complicated snowpack properties. In a comparison of SWE derived from the empirical SCA relationship to SWE estimated from the Snow Data Assimilation product, we find substantial quantitative improvement over the passive microwave SWE product during the spring melt season.

\section{SUBJECT TERMS}

Hydrologic models, Hydrology, Melt, Model, MODIS, Prediction, Red River of the North, Runoff, Satellite, Snow

\section{SECURITY CLASSIFICATION OF:}

\section{a. REPORT}

Unclassified

\section{b. ABSTRACT}

Unclassified

\section{c. THIS PAGE}

Unclassified
17. LIMITATION OF ABSTRACT

SAR
18. NUMBER OF PAGES

32 19a. NAME OF RESPONSIBLE PERSON

19b. TELEPHONE NUMBER (include area code) 